www.volsu.ru

DOI: https://doi.org/10.15688/jvolsu3.2017.3.3

UDC 338.26:658.1

LBC 65.050

\title{
INTEGRATION OF BUSINESS, EDUCATION AND SCIENCE AT THE REGIONAL LEVEL FOR IMPLEMENTING THE NATIONAL TECHNOLOGICAL INITIATIVE ${ }^{1}$
}

\author{
Innara R. Lyapina
}

Orel State University named after I.S. Turgenev, Orel, Russian Federation

Olesya A. Stroeva

Central Russian Institute of Management - Branch of Russian Presidential Academy of National Economy and Public Administration, Orel, Russian Federation

\begin{abstract}
Current world affairs show that the post-industrial stage of development of all mature world powers' economies is followed by creation of a new development paradigm, which is based on the economy of knowledge, science achievements, innovations, global information and communication systems, and which leads to innovative economy formation.

In the context of the national innovation economy formation in the Russian Federation, prerequisites are created for integrating the efforts of business, science and education representatives to develop, produce and market high-tech products which have significant economic or social potential. And this is not only the task announced by the Russian government, but also a natural process in the country's economy, which contributes to the increase in the integration participants' efficiency. The result of such integrated interaction of education, science and business consists in a synergistic effect through formation of an interactive cooperation model that involves the active use of combined knowledge, ideas, technologies and other resources during innovative projects implementation.

At the same time, integration processes are diverse, complex and occur in each case taking into account the integrating parties' activity specifics. Within this framework, the goal of the research is to characterize the impact of the education, science and business integration process, on the national technological initiative implementation in the country on the whole and to study the integrating experience of these entities at the regional level.

In the course of the research, the stages of the Russian national innovation economy formation process have been studied; the role of education, science and business in the National Technological Initiative implementation has been characterized; it's been proved that educational institutions are the key link in the integration process in the chain "education - science - business"; the experience of education, science and business integration in the regions of Russia has been studied.

As a result of the research, the authors emphasize the necessity of preferring soft forms of education, science and business integration at the regional level, as they allow to preserve the flexibility of integrated structures and also to make necessary adjustments to the membership and implemented innovative projects in order to solve the pressing tasks of National Technological Initiative.
\end{abstract}

Key words: integration, national innovative economy, national technological initiative, integration of education, science and business, integration forms.

УДК 338.26:658.1

ББК 65.050

\section{ИНТЕГРАЦИЯ БИЗНЕСА, ОБРАЗОВАНИЯ И НАУКИ НА РЕГИОНАЛЬНОМ УРОВНЕ В ЦЕЛЯХ РЕАЛИЗАЦИИ НАЦИОНАЛЬНОЙ ТЕХНОЛОГИЧЕСКОЙ ИНИЦИАТИВЫ ${ }^{1}$}

\author{
Иннара Рафаильевна Ляпина
}

Орловский государственный университет им. И.С. Тургенева, г. Орел, Российская Федерация 


\section{Олеся Анатольевна Строева}

Среднерусский институт управления - филиал Российской академии народного хозяйства и государственной службы при Президенте Российской Федерации, г. Орел, Российская Федерация

Аннотация. Сложившаяся в мире ситуация показывает, что следующим за постиндустриальным этапом развития экономик всех развитых мировых держав является создание новой парадигмы развития, базирующейся на экономике знаний, достижениях науки, инновациях, глобальных информационно-коммуникационных системах и ведущей к построению инновационной экономики.

В условиях формирования национальной инновационной экономики в Российской Федерации создаются предпосылки для интеграции усилий представителей бизнеса, науки и образования по разработке, производству и реализации высокотехнологических продуктов, обладающих значительным экономическим или социальным потенциалом. И это не только задача, озвученная Правительством России, но и естественный процесс в экономике страны, способствующий повышению эффективности деятельности всех участников интеграции. В результате интегрированного взаимодействия образования, науки и бизнеса возникает синергический эффект за счет формирования интерактивной модели взаимодействия, предполагающий активное использование объединенных знаний, идей, технологий и прочих ресурсов при реализации инновационных проектов.

При этом интеграционные процессы многообразны, сложны и протекают в каждом случае с учетом специфики деятельности интегрирующихся сторон. В этой связи целью исследования является характеристика воздействия процесса интеграции образования, науки и бизнеса на реализацию национальной технологической инициативы в целом по стране и изучение опыта интеграции указанных субъектов на региональном уровне.

В ходе исследования были изучены этапы процесса формирования национальной инновационной экономики России; охарактеризована роль образования, науки и бизнеса в реализации Национальной технологической инициативы; доказано, что образовательные учреждения являются ключевым звеном в интеграционном процессе по цепочке «образование - наука - бизнес»; изучен опыт интеграции образования, науки и бизнеса по регионам России.

В итоге проведенного исследования подчеркивается необходимость предпочтения мягких форм интеграции образования, науки и бизнеса на региональном уровне, поскольку именно они позволяют сохранять гибкость интегрированных структур и допускают внесение необходимых корректив в состав участников и реализуемые инновационные проекты в целях решения насущных задач Национальной технологической инициативы.

Ключевые слова: интеграция; национальная инновационная экономика; национальная технологическая инициатива; интеграция образования, науки и бизнеса; формы интеграции.

\section{Особенности интеграции образования, науки и бизнеса при реализации Национальной технологической инициативы}

Процесс формирования национальной инновационной экономики России в своем развитии прошел ряд этапов (см. рис. 1) и в настоящее время нацелен на реализацию комплексной программы «Национальная технологическая инициатива».

Данная программа включает системные решения по определению ключевых технологий, необходимых изменений в области норм и правил, работающих мер финансового и кадрового развития, механизмов вовлечения и вознаграждения носителей необходимых компетенций [11]. Она предполагает скоординированную работу всех заинтересо- ванных лиц (ведущих научных и образовательных организаций, крупных и средних производственных предприятий, субъектов малого предпринимательства, общественных объединений) в целях обеспечения глобального технологического паритета России и стран - технологических лидеров, а также подготовки национальных компаний к работе на принципиально новых отраслевых рынках, составляющих будущую основу мировой экономики (см. табл. 1).

В этой связи успех мероприятий в рамках НТИ во многом зависит от качества координации усилий в этой области образования, науки и бизнеса. Чаще всего необходимость согласования действий побуждает образовательные учреждения, науку и бизнес не просто обсуждать варианты совместных действий, а интегрировать свою деятельность. 


\begin{tabular}{|c|c|}
\hline 2006 год & $\begin{array}{l}\text { Реализация приоритетных национальных проектов, имеющих инновационную направлен- } \\
\text { ность (проекты «Здоровье», «Образование» и т. д.) }\end{array}$ \\
\hline \multicolumn{2}{|r|}{ } \\
\hline 2007 год & $\begin{array}{l}\text { Создание госкорпораций, нацеленных на разработку, производство и экспорт высокотехно- } \\
\text { логичной промышленной продукции (Роснано, Ростех, Росатом и т. д.) }\end{array}$ \\
\hline \multicolumn{2}{|r|}{ P } \\
\hline $\begin{array}{c}2011- \\
2014 \text { годы }\end{array}$ & $\begin{array}{l}\text { Создание технологических платформ для кооперации действий государства, бизнеса и науки } \\
\text { при выявлении векторов инновационного развития (созданы по } 35 \text { направлениям) }\end{array}$ \\
\hline गु & \\
\hline $\begin{array}{c}2014- \\
2035 \text { годы }\end{array}$ & $\begin{array}{l}\text { Приоритетом государственной политики становится национальная технологическая инициа- } \\
\text { тива - долгосрочная комплексная программа, опирающаяся на дорожные карты (EnergyNet, } \\
\text { FoodNet, SafeNet, HealthNet, AeroNet, MariNet, AutoNet, FinNet, NeuroNet) }\end{array}$ \\
\hline
\end{tabular}

Рис. 1. Этапы процесса формирования национальной инновационной экономики России

Примечание. Составлено авторами.

\section{Роль образования, науки и бизнеса в реализации НТИ}

\begin{tabular}{|c|c|c|}
\hline $\begin{array}{c}\text { Участники } \\
\text { НТИ }\end{array}$ & Цель в рамках НТИ & Факторы, побуждающие к интеграции \\
\hline Образование & $\begin{array}{l}\text { Подготовка специалистов с иннова- } \\
\text { ционным мышлением, обладающих } \\
\text { профессиональными и межпрофес- } \\
\text { сиональными компетенциями, необ- } \\
\text { ходимыми в будущей работе, и ус- } \\
\text { пешно способных осуществять бу- } \\
\text { дущие трудовые функции в условиях } \\
\text { конкуренции }\end{array}$ & $\begin{array}{l}\text { - необходимо развитие практических навыков, инно- } \\
\text { вационных и предпринимательских способностей } \\
\text { обучающихся; } \\
\text { - недостаточно средств на НИР; } \\
\text { - необходимо внедрять междисциплинарный подход } \\
\text { к образованию; } \\
\text { - затруднены демонстрация возможностей и исполь- } \\
\text { зование современной техники и технологий, исполь- } \\
\text { зуемых предприятиями, в ходе учебного процесса }\end{array}$ \\
\hline Наука & $\begin{array}{l}\text { Приращение знаний, открытие новых } \\
\text { свойств и закономерностей иссле- } \\
\text { дуемых объектов, развитие экономи- } \\
\text { ческого потенциала общества, созда- } \\
\text { ние новых потребительских стоимо- } \\
\text { стей }\end{array}$ & $\begin{array}{l}\text { - коммерциализация научных разработок затруднена; } \\
\text { - необходимо расширение областей применения ин- } \\
\text { новационных разработок; } \\
\text { - повышается значимость прикладных исследований, } \\
\text { учитывающих интересы конкретных отраслей / пред- } \\
\text { приятий }\end{array}$ \\
\hline Бизнес & $\begin{array}{l}\text { Развитие высокотехнологических } \\
\text { производств, работа на новых рын- } \\
\text { ках, высокие темпы развития }\end{array}$ & $\begin{array}{l}\text { - необходимы технологии, позволяющие реализовать } \\
\text { стратегические цели компании; } \\
\text { - развитие новых технологий требует научной прора- } \\
\text { ботки; } \\
\text { - нужны специалисты, способные реализовывать ин- } \\
\text { новационные проекты, осваивать новые области зна- } \\
\text { ний и приобретать новые умения и компетенции, а } \\
\text { также использовать их в рамках конкретного произ- } \\
\text { водственного процесса; } \\
\text { - необходимо обеспечить непрерывный процесс обу- } \\
\text { чения персонала; } \\
\text { - требуется постоянное совершенствование выпус- } \\
\text { каемой продукции / услуг с учетом трансформации } \\
\text { запросов потребителей; } \\
\text { - необходимо расширение информационного поля за } \\
\text { счет обеспечения доступа к научно-исследо- } \\
\text { вательской базе и информационным ресурсам образо- } \\
\text { вательных учреждений }\end{array}$ \\
\hline
\end{tabular}

Примечание. Составлено по: [1;11;16]. 


\section{МЕЖДУНАРОДНЫЕ ИНТЕГРАЦИОННЫЕ ПРОЦЕССЫ}

Центральным звеном интеграционных процессов между образованием, наукой и бизнесом чаще всего являются образовательные учреждения в лице университетов. Дело в том, что в последнее время именно образование стало доминирующим фактором социально-экономического развития и обеспечения конкурентоспособности национальной экономики. Причин этому несколько [1; 6;9]:

1. Роль и место знаний в развитии экономики существенно возросли. Без них на данный момент невозможна организация ни одного высокотехнологического производственного процесса.

2. Образование позволяет организовать более быстрый процесс включения новых знаний в хозяйственную практику.

3. Вузы становятся все чаще генераторами инновационных процессов. Другие же субъекты экономики (государства и бизнессообщество) выступают преимущественно в роли заказчиков, потребителей и соинвесторами инновационных проектов.

4. Современные инновации формируются на базе нескольких десятков научных достижений, часто относящихся к различным областям знаний. И именно в стенах образовательных учреждений специалисты разных научных профилей получают возможность координировать свои действия.

\section{Особенности интеграции образования, науки и бизнеса на региональном уровне}

На региональном уровне интеграционные процессы в цепочке «образование - наука бизнес» протекают по разному, принимая разные формы и масштабы (см. табл. 2).

Их анализ свидетельствует о том, что интеграционные процессы в цепочке «образование - наука - бизнес» представляют собой длительный исторически сложившийся процесс, в значительной мере обусловленный неформальными институтами и представлениями о наиболее рациональных методах решения поставленных задач лицами, принимающими решения в рамках конкретных образовательных организаций. Именно представление менеджмента организаций о региональных особенностях является движущим началом интеграции.
Применение конкретных институтов (технопарков, малых инновационных предприятий и прочих форм интеграции) обусловлено уровнем развития институционального поля интеграционного процесса и в значительной мере «модой» на тот или иной институт. В свою очередь, «мода» формировалась государством, так как была связана с возможностью участия в определенных государственных программах и получением дополнительного финансирования. По мере того как «мода» приходила или уходила, конкретные сложившиеся практики либо институциализировались в виде общепринятых форм и разрабатываемых внутренних документов, с ними связанных, либо ликвидировались.

Независимо от используемой формы интеграции она впоследствии вызывала ряд позитивных сдвигов:

- существенно расширяется информационная база, позволяющая обеспечить студентов актуальной информацией о рынке труда и организовать им практико-ориентированное обучение;

- увеличивается количество совместных научно-исследовательских проектов и упрощается их финансирование;

- бизнес получает доступ к управлению образовательными учреждениями через участие в разработке образовательных программ, осуществление оценки соответствия выпускников профессиональным стандартам, мониторинг деятельности образовательного учреждения и т. д.

\section{Заключение}

Если рассматривать интеграцию образования, науки и бизнеса на региональном уровне, то следует отметить следующее:

1. В экономике большинства регионов отсутствует явно выраженная доминирующая отрасль. Поэтому в процессе интеграции подбор участников целесообразно осуществлять таким образом, чтобы сформированное объединение позволило обеспечить максимальное соответствие спроса и предложения рабочих кадров и специалистов требованиям регионального рынка труда и перспективам его социально-экономического развития в рамках НТИ. 
Примеры интеграционных процессов в цепочке «образование - наука - бизнес» по регионам России

\begin{tabular}{|c|c|}
\hline Наименование организации & $\begin{array}{c}\text { Институциональное решение при интеграции } \\
\end{array}$ \\
\hline $\begin{array}{lr}\text { Санкт-Петербургский } & \text { государ- } \\
\text { ственный электротехнический } \\
\text { университет и его учебно- } \\
\text { научно-инновационный } \\
\text { плекс }\end{array}$ & $\begin{array}{l}\text { Одной из базовых интеграционных структур в данном случае яв- } \\
\text { ляется технопарк }[2 ; 12]\end{array}$ \\
\hline $\begin{array}{l}\text { Новгородский государственный } \\
\text { университет им. Ярослава Муд- } \\
\text { рого }\end{array}$ & $\begin{array}{l}\text { Данная образовательная организация была сформирована на базе } \\
\text { трех вузов, являясь прототипом опорных вузов, для которых сре- } \\
\text { ди обязательного условия выступало требование реорганизации в } \\
\text { форме слияния, объединения или присоединения [3] }\end{array}$ \\
\hline $\begin{array}{l}\text { Сибирский государственный } \\
\text { технологический университет и } \\
\text { Якутский государственный уни- } \\
\text { верситет }\end{array}$ & $\begin{array}{l}\text { Здесь заявлены в качестве интеграторов технопарки, в названиях } \\
\text { которых фигурирует слово «бизнес-инкубатор» [7; 14] }\end{array}$ \\
\hline $\begin{array}{lr}\text { Саратовский } & \text { государственный } \\
\text { технический } & \text { университет } \\
\text { им. Ю.А. Гагарина }\end{array}$ & $\begin{array}{l}\text { Еще до институционализации МИПов отмечается совместная } \\
\text { деятельность с Саратовским подшипниковым заводом [8] }\end{array}$ \\
\hline $\begin{array}{l}\text { Южно-Уральский государствен- } \\
\text { ный университет }\end{array}$ & $\begin{array}{l}\text { Его роль в интеграционных процессах в регионе рассматривается } \\
\text { с позиций формирования элементов инфраструктуры [5] }\end{array}$ \\
\hline $\begin{array}{l}\text { Томский политехнический уни- } \\
\text { верситет }\end{array}$ & $\begin{array}{l}\text { На его примере хорошо прослеживается внутренняя институцио- } \\
\text { нализация инновационного трансферта на примере регламентов } \\
\text { функционирования Управления по инновационной и производст- } \\
\text { венной деятельности, в задачи которого входит координация } \\
\text { взаимодействия с внешними и внутренними агентами [4] }\end{array}$ \\
\hline $\begin{array}{l}\text { Нижегородский государственный } \\
\text { университета им. Н.И. Лобачев- } \\
\text { ского }\end{array}$ & $\begin{array}{l}\text { Здесь создан «Нижегородский объединенный учебно-научный } \\
\text { центр университета и институтов РАН», являющийся примером } \\
\text { горизонтальных интеграционных процессов в образовании [17] }\end{array}$ \\
\hline $\begin{array}{l}\text { Новосибирский } \\
\text { ный университет }\end{array}$ & $\begin{array}{l}\text { Здесь интеграционные процессы институционализированы в виде } \\
\text { Программы развития инновационной инфраструктуры НГУ «Ин- } \\
\text { новационная платформа для конвергенции образования, науки и } \\
\text { бизнеса на базе классического университета» [13] }\end{array}$ \\
\hline 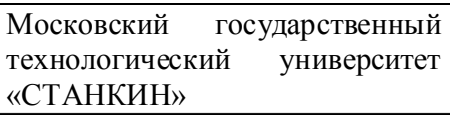 & $\begin{array}{l}\text { Интеграционные процессы с его участием привели к формирова- } \\
\text { нию пояса малых инновационных предприятий [10] }\end{array}$ \\
\hline $\begin{array}{l}\text { Московский государственный } \\
\text { институт электронной техники и } \\
\text { его Зеленоградский научно- } \\
\text { техно-логический парк }\end{array}$ & $\begin{array}{l}\text { Может рассматриваться как кластерообразующая компания сво- } \\
\text { его региона [15] }\end{array}$ \\
\hline
\end{tabular}

2. Выбор форм интеграции образования, науки и бизнеса зависит:

- от лиц, принимающих решения (определяется системой взглядов менеджмента организаций на региональные особенности); рации;

- «моды» на ту или иную форму интег-

- возможности участия в специальных государственных программах, предполагающих дополнительное финансирование.

3. При выборе форм интеграции целесообразно отдавать предпочтение «мягким» формам (стратегические альянсы и т. п.). Они позволяют вести совместную деятельность при сохранении участниками интеграционных процессов юридической и хозяйственной самостоятельности. В ре- зультате формируемая структура становится гибкой и допускает возможность изменения качественного и количественного состава участников в целях реализации насущных задач НТИ.

\section{ПРИМЕЧАНИЕ}

1 Данное исследование выполнено при финансовой поддержке Российского экономического университета им. Г.В. Плеханова.

\section{СПИСОК ЛИТЕРАТУРЫ}

1. Байкова, О. М. Интеграция образования, науки и бизнеса как условие эффективного разви- 
тия экономики России / О. М. Байкова, М. А. Сухомлинова // Государственное управление. Электронный вестник. - 2010. - № 23. - С. 1-7.

2. Взаимодействие с промышленностью региона - важнейшая задача деятельности УНИК многопрофильного технического вуза / Д. В. Пузанков [и др.] // Инновации. - 2001. - № 1-2.

3. Гантмахер, В. Е. Создание мощного университета - одна из приоритетных задач на пути инновационного развития региона / В. Е. Гантмахер // Инновации. - 2001. - № 1-2. - С. 35-38.

4. Дмитриенко, В. П. Развитие инновационной инфраструктуры вуза и коммерциализация научных разработок на примере ТПУ начальник управления по инновационной и производственной деятельности, 2015 / В. П. Дмитриенко, В. В. Негруль. - Электpoн. текстовые дан. - Режим доступа: http:/www. manotom-tmz.ru/media/konferen/prezentachii/8.pdf. Загл. с экрана.

5. Досужева, Е. Е. О современных особенностях формирования инновационной инфраструктуры с участием вузов в Российской Федерации (часть 1) / Е. Е. Досужева, О. Л. Лямзин // Проблемы современной экономики. - 2012. № 1. - С. 383-387.

6. Есина, Ю. Л. Формы и механизмы интеграции науки, образования и бизнес-сообщества в условиях инновационного обновления региональной экономики / Ю. Л. Есина, Н. М. Степаненкова, Е. Е. Агафонова // Креативная экономика. - 2015. T. 9, № 12. - С. 1491-1508.

7. Заровняев, Б. Н. Проблемы активизации инновационной деятельности вузов региона / Б. Н. Заровняев, Г. С. Ковров, Н. Е. Егоров // Инновации. - 2001. - № 1-2. - С. 65.

8. Коссович, Л. Ю. Направления развития научной и инновационной деятельности в Саратовском государственном университете / Л. Ю. Коссович, Д. А. Усанов // Инновации. - 2005. - № 6. С. $61-63$.

9. Кузнецов, П. М. Интеграция науки, образования и бизнеса как элементов национальной инновационной системы РФ / П. М. Кузнецов // Вестник Томского государственного педагогического университета. - 2013. - № 12 (140). - С. 91-94.

10. Лукашевич, Е. В. Проблемы и перспективы инновационного предпринимательства в вузах на примере ФГБОУ ВПО Московский государственный технологический университет «СТАНКИН» / Е. В. Лукашевич, А. Л. Храмцов // Инновации. 2013. - № 10 (180). - С. 6-9.

11. Национальная технологическая инициатива : офиц. сайт. - Электрон. текстовые дан. - Режим доступа: https://asi.ru/nti/. - Загл. с экрана.

12. Основные этапы развития Технопарка Санкт-Петербургского государственного электротех- нического университета «ЛЭТИ» / А. Д. Викторов [и др.] // Инновации. - 2005. - № 6 (83). - С. 57-61.

13. Программа развития инновационной инфраструктуры НГУ, 2010. - Электрон. текстовые дан. - Режим доступа: http://inno.nsu.ru/center/201009-30.htm. - Загл. с экрана.

14. Роль учебно-научно-инновационных комплексов в активизации региональной инновационной деятельности / Э. С. Бука [и др.] // Инновации. 2001. - № 1-2. - С. 61.

15. Рыгалин, Д. Б. Опыт формирования высокотехнологичных отраслевых кластеров / Д. Б. Рыгалин // Инновационный вестник Регион. - 2006. № 6. - С. 50-59.

16. Сагдатуллин, А. М. Интеграция науки, образования, производства и бизнеса как основа повышения эффективности региональной системы профессионального образования / А. М. Сагдатуллин // Вестник Адыгейского государственного университета. -2014. - Вып. 1 (132). - С. 46-51.

17. Стронгин, Р. Г. Интеграция как пугь повышения качества и востребованности высшего образования / Р. Г. Стронгин, С. Н. Курбатов, А. В. Петров. Н. Новгород : Изд-во Нижегор. гос. ун-та, 2006. - 24 с.

\section{REFERENCES}

1. Baykova O.M., Sukhomlinova M.A. Integratsiya obrazovaniya, nauki i biznesa kak uslovie effektivnogo razvitiya ekonomiki Rossii [Integration of Education, Science and Business as a Condition of Effective Development of Russian Economy]. Gosudarstvennoe upravlenie. Elektronnyy vestnik, 2010, no. 23, pp. 1-7.

2. PuzankovD.V., Kutuzov V.M,. ShestopalovM.Yu., Kupriyanov M.S. Vzaimodeystvie s promyshlennostyu regiona - vazhneyshaya zadacha deyatelnosti UNIK mnogoprofilnogo tekhnicheskogo vuza [Interaction with the Industry of the Region - the Most Important Task of Activity of UNIK Versatile Technical College]. Innovatsii, 2001, no. 1-2.

3. Gantmahher V.E. Sozdanie moshchnogo universiteta - odna iz prioritetnykh zadach na puti innovatsionnogo razvitiya regiona [Creation of Powerful University as One of Priority Tasks on the Way of Innovative Development of the Region]. Innovatsii, 2001, no. 1-2, pp. 35-38.

4. Dmitrienko V.P., Negrul V.V. Razvitie innovatsionnoy infrastruktury vuza i kommertsializatsiya nauchnykh razrabotok na primere TPU, 2015 [Development of Innovative Infrastructure of Higher Education Institution and Commercialization of Scientific Developments on the Example of TPU, 2015]. URL: http:// www.manotom-tmz.ru/media/konferen/prezentachii/8.pdf (accessed March 24, 2017). 
И.Р. Ляпина, О.А. Строева. Интеграция бизнеса, образования и науки на региональном уровне

5. Dosuzheva E.E., Lyamzin O.L. O sovremennykh osobennostyakh formirovaniya innovatsionnoy infrastruktury s uchastiem vuzov v Rossiyskoy Federatsii (chast 1) [About Modern Features of Innovative Infrastructure Formation with Participation of Higher Education Institutions in the Russian Federation (Part 1)]. Problemy sovremennoy ekonomiki, 2012, no. 1, pp. 383-387.

6. Esina Yu.L., Stepanenkova N.M., Agafonova E.E. Formy i mekhanizmy integratsii nauki, obrazovaniya $\mathrm{i}$ biznes-soobshchestva $\mathrm{v}$ usloviyakh innovatsionnogo obnovleniya regionalnoy ekonomiki [Forms and Mechanisms of Integration of Science, Education and Business Community in the Conditions of Innovative Updating of Regional Economy]. Kreativnaya ekonomika, 2015, vol. 9, no. 12, pp. 1491-1508.

7. Zarovnyaev B.N., Kovrov G.S., Egorov N.E. Problemy aktivizatsii innovatsionnoy deyatelnosti vuzov regiona [Problems of Activization of Innovative Activity of Higher Education Institutions of the Region]. Innovatsii, 2001, no. 1-2, p. 65.

8. Kossovich L.Yu., Usanov D.A. Napravleniya razvitiya nauchnoy i innovatsionnoy deyatelnosti $\mathrm{v}$ Saratovskom gosudarstvennom universitete [The Directions of Development of Scientific and Innovative Activity at the Saratov State University]. Innovatsii, 2005, no. 6, pp. 61-63.

9. Kuznetsov P.M. Integratsiya nauki, obrazovaniya i biznesa kak elementov natsionalnoy innovatsionnoy sistemy RF [Integration of Science, Education and Business as Elements of the National Innovative System of the Russian Federation]. Vestnik Tomskogo gosudarstvennogo pedagogicheskogo universiteta, 2013, no. 12 (140), pp. 91-94.

10. Lukashevich E.V., Khramtsov A.L. Problemy i perspektivy innovatsionnogo predprinimatelstva $\mathrm{V}$ vuzakh na primere FGBOU VPO Moskovskiy gosudarstvennyy tekhnologicheskiy universitet «STANKIN» [Problems and Prospects of Innovative Business in Higher Education Institutions on the Example of Moscow State Technological University “STANKIN"]. Innovatsii, 2013, no. 10 (180), pp. 6-9.
11. Natsionalnaya tekhnologicheskaya initsiativa: ofits. sayt [National Technological Initiative: Official Site]. URL: https://asi.ru/nti/ (accessed March 24, 2017).

12. Viktorov A.D., Ermilov N.N., Kutuzov V.M., Vinogradov A.B., Ryzhov N.G., Shestopalov M.Yu. Osnovnye etapy razvitiya Tekhnoparka SanktPeterburgskogo gosudarstvennogo elektrotekhnicheskogo universiteta 'LETI" [Main Stages ofDevelopment of Science and Technology Park of St. Petersburg State Electrotechnical University “LETI"]. Innovatsii, 2005, no. 6(83), pp. 57-61.

13. Programma razvitiya innovatsionnoy infrastruktury NGU, 2010 [Program of Development of Innovative Infrastructure of NSU, 2010]. URL: http://inno.nsu.ru/center/2010-09-30.htm. (accessed March 24, 2017).

14. Buka E.S., Repyakh S.M., Pavlov I.N., Nevzorov V.N., Nemich V.N. Rol uchebno-nauchnoinnovatsionnykh kompleksov $\mathrm{V}$ aktivizatsii regionalnoy innovatsionnoy deyatelnosti [The Role of Educational and Scientific and Innovative Complexes in Activization of Regional Innovative Activity]. Innovatsii, 2001, no. 1-2, p. 61.

15. Rygalin D.B. Opyt formirovaniya vysokotekhnologichnykh otraslevykh klasterov [Experience of Formation of Hi-Tech Branch Clusters]. Innovatsionnyy vestnik Region, 2006, no. 6, pp. 50-59.

16. Sagdatullin A.M. Integratsiya nauki, obrazovaniya, proizvodstva i biznesa kak osnova povysheniya effektivnosti regionalnoy sistemy professionalnogo obrazovaniya [Integration of Science, Education, Production and Business as a Basis of Increase in Efficiency of Regional System of Professional Education]. Vestnik Adygeyskogo gosudarstvennogo universiteta, 2014, no. 1 (132), pp. 46-51.

17. Strongin R.G., Gurbatov S.N., Petrov A.V. Integratsiya kak put povysheniya kachestva $i$ vostrebovannosti vysshego obrazovaniya [Integration as a Way of Improving the Quality and Increasing Demand for the Higher Education]. Nizhny Novgorod, Izd-vo Nizhegor. gos. un-ta, 2006. 24 p.

\section{Information about the Authors}

Innara R. Lyapina, Doctor of Sciences (Economics), Associate Professor, Professor of Department of Marketing, Orel State University named after I.S. Turgenev, Komsomolskaya St., 95, 302026 Orel, Russian Federation, innara_lapina@mail.ru.

Olesya A. Stroeva, Doctor of Sciences (Economics), Associate Professor, Professor of Department of Economy and Economic Security, Central Russian Institute of Management - Branch of Russian Presidential Academy of National Economy and Public Administration, Pobedy Boulevard, 5a, 302028 Orel, Russian Federation, stroeva-olesya@mail.ru. 


\section{Информация об авторах}

Иннара Рафаильевна Ляпина, доктор экономических наук, доцент, профессор кафедры маркетинга, Орловский государственный университет им. И.С. Тургенева, ул. Комсомольская, 95, 302026 г. Орел, Российская Федерация, innara_lapina@mail.ru.

Олеся Анатольевна Строева, доктор экономических наук, доцент, профессор кафедры экономики и экономической безопасности, Среднерусский институт управления - филиал Российской академии народного хозяйства и государственной службы при Президенте Российской Федерации, бульвар Победы, 5а, 302028 г. Орел, Российская Федерация, stroeva-olesya@mail.ru. 